\title{
Gene expression profiles of tumor regression grade in locally advanced rectal cancer after neoadjuvant chemoradiotherapy
}

\author{
SUSUMU SAIGUSA, KOJI TANAKA, YUJI TOIYAMA, KOHEI MATSUSHITA, MIKIO KAWAMURA, \\ YOSHINAGA OKUGAWA, JUNICHIRO HIRO, YASUHIRO INOUE, KEIICHI UCHIDA, \\ YASUHIKO MOHRI and MASATO KUSUNOKI
}

Department of Gastrointestinal and Pediatric Surgery, Mie University Graduate School of Medicine, Mie 514-8507, Japan

Received March 26, 2012; Accepted May 18, 2012

DOI: $10.3892 /$ or.2012.1863

\begin{abstract}
Tumor regression grading (TRG) reportedly has prognostic value in rectal cancer patients after pre-operative chemoradiotherapy (CRT). The aim of this retrospective study was to differentiate gene expression profiles based on TRG in residual cancer cells after CRT. We evaluated pathological response using the criteria of four TRG systems: the Japanese Society for the Cancer of Colon and Rectum (JSCCR), Mandard, Dworak and Rödel. Total RNA was obtained using microdissection from 52 locally advanced rectal cancer specimens from patients who underwent pre-operative CRT to examine the expression levels of 20 genes [PCNA, MKI67, CDKN1A ( $21^{\text {Cipl }), C D K 2, C H E K 1, ~ P D R G 1, ~ L G R 5, ~ P R O M 1 ~}$ (CD133), CD44, SOX2, POU5F1 (OCT4), LKB1, VEGF, EGFR, $H G F, M E T, H I F 1, G L U T 1, B A X$ and BCL2] using real-time quantitative RT-PCR. Gene expression was compared across the four TRG systems. LGR5 gene expression levels in CRT non-responders were significantly higher than in responders in all four grading systems. Patients with elevated PDRG1 and GLUT1 gene expression had poor pathological response in three TRG systems (JSCCR, Dworak and Rödel). MKI67 gene expression in non-responders was significantly higher than in responders in two grading systems (JSCCR and Rödel). While, $B A X$ gene expression in responders was significantly higher than in non-responders in the Mandard TRG system. The results of this study suggest that TRG may reflect characteristics, such as proliferative activity, stemness potency and resistance to hypoxia, of residual cancer cells following pre-operative CRT.
\end{abstract}

Correspondence to: Dr Susumu Saigusa, Department of Gastrointestinal and Pediatric Surgery, Mie University Graduate School of Medicine, 2-174 Edobashi, Tsu, Mie 514-8507, Japan

E-mail: saigusa@clin.medic.mie-u.ac.jp

Key words: gene expression profiles, tumor regression grade, neoadjuvant chemoradiotherapy, rectal cancer

\section{Introduction}

Pre-operative CRT followed by surgery is the standard treatment for patients with locally advanced rectal cancer. However, disease recurrence remains the major cause of mortality in these patients $(1,2)$. Identifying predictors for disease recurrence or poor prognosis would aid in the successful treatment of these patients. Tumor regression grade (TRG) following preoperative CRT is determined by quantifying the proportion of residual cancer cells to the stroma of the entire tumor bed. In rectal cancer, several studies have found that TRG or pathologic response is a predictor of clinical outcome, including disease recurrence and survival (3-8). Hence, it is possible that gene expression correlated with TRG might reflect the characteristics, including resistance to CRT, of residual cancer cells and might be associated with prognosis in patients with rectal cancer after pre-operative CRT. DNA repair pathways (9), cell cycle pathways $(10)$, hypoxia $(11,12)$, anti-apoptosis (13) and cancer stem cells $(14,15)$ have been implicated in the mechanisms of CRT resistance. Twenty genes were selected for a comparison in expression levels between CRT responders and non-responders: PCNA and MKI67 (Ki67) as proliferative markers; $C D K N 1 A\left(p 21^{C i p l}\right)$ and $C D K 2$ as cell cycle associated markers after irradiation; $C H E K 1$ and $P D R G 1$ (p53 and DNA downregulated gene) as DNA damage associated makers; LGR5, PROM1 known as CD133, CD44, SOX2, POU5F1 known as OCT4 and $L K B I$ known as $S K T 11$, as stem cell associated markers; VEGFA, $H G F$ and MET as growth factors; $H I F 1$ and GLUT1 as hypoxia associated markers; $B A X$ and $B C L 2$ as apoptosis associated markers in this transcriptional analysis. The aim of this retrospective study was to examine the expression of certain genes in TRGs and determine if the two are associated with clinical outcome in patients with locally advanced rectal cancer after pre-operative CRT.

\section{Materials and methods}

Patients and specimens. From 2001 to 2008, 64 patients with rectal cancer received pre-operative CRT followed by surgery at Mie University Hospital. The following criteria were used for induction of pre-operative CRT. Patients must i) be no more 
Table I. Primer sequences of target genes.

\begin{tabular}{|c|c|c|}
\hline Gene symbol & Forward & Reverse \\
\hline PCNA & GAAGCACCAAACCAGGAGAA & TATCGGCATATACGTGCAAA \\
\hline MKI67 & TGAGCCTGTACGGCTAAAACA & TTGACTTCCTTCCATTCTGAAG \\
\hline$C D K N 1 A$ & GACTCTCAGGGTCGAAAACG & GGATTAGGGCTTCCTCTTGG \\
\hline$C D K 2$ & САТТССТСТТССССТСАТСА & TTTAAGGTCTCGGTGGAGGA \\
\hline CHEK1 & GACTGGGACTTGGTGCAAAC & CACTGCGACTGATTCAG \\
\hline PDRG1 & CCTCACCCTGAGACAAAGGA & GGCGGTTGACCTTCACTTTA \\
\hline$L G R 5$ & GATGTTGCTCAGGGTGGACT & GGGAGCAGCTGACTGATGTT \\
\hline PROMI & GCTTTGCAATCTCCCTGTTG & TTGATCCGGGTTCTTACCTG \\
\hline$C D 44$ & CGGACACCATGGACAAGTTT & CACGTGGAATACACCTGCAA \\
\hline SOX2 & CAAGATGCACAACTCGGAGA & GCTTAGCCTCGTCGATGAAC \\
\hline POU5F1 & CTGGAGAAGGAGAAGCTGGA & CAAATTGCTCGAGTTCTTTCTG \\
\hline$L K B 1$ & CTCTTACGGCAAGGTGAAGG & TTGTGCCGTAACCTCCTCAG \\
\hline$V E G F A$ & CAGAAGGAGGAGGGCAGAA & CTCGATTGGATGGCAGTAGC \\
\hline$E G F R$ & CCTATGTGCAGAGGAATTATGATCTTT & CCACTGTGTTGAGGGCAATG \\
\hline$H G F$ & ATTTGGCCATGTTTTGACC & AGCTGCGTCCTTTACCAATG \\
\hline$M E T$ & AGGTGTGGGAAAAACCTGA & ATTCAGCTGTTGCAGGGAAG \\
\hline$H I F 1$ & CCGCTGGAGACACAATCATA & СTTCCTCAAGTTGCTGGTCA \\
\hline GLUT1 & CCTGCAGTTTGGCTACAACA & GTGGACCCATGTCTGGTTG \\
\hline$B A X$ & CTTTGCCAGCAAACTGGTG & CAGCCCATGATGGTTCTGA \\
\hline$B C L 2$ & TCGCCCTGTGGATGACTGA & CAGAGACAGCCAGGAGAAATCAA \\
\hline$G A P D H$ & GGAAGGTGAAGGTCGGAGTC & AATGAAGGGGTCATTCATGG \\
\hline$A C T B$ & ACAGAGCCTCGCCTTTGC & GCGGCGATATCATCATCC \\
\hline
\end{tabular}

$P C N A$, proliferation cell nuclear antigen; MKI67, Ki67; CDKN1A, $p 21^{C i p 1} ; C D K 2$, cyclin-dependent kinase 2; PDRG1, p53 and DNA-damage regulated 1; LGR5, leucine-rich repeat-containing G protein-coupled receptor 5 known as GPR49; CHEK1, checkpoint kinase 1; PROM1, CD133; POU5F1, OCT4; LKB1, serine/threonine kinase 11 known as STK11; VEGFA, vascular endothelial growth factor; EGFR, epidermal growth factor receptor; $H G F$, hepatocyte growth factor; $M E T$, HGF receptor; $H I F 1$, hypoxia inducible factor $1 \alpha$; GLUT1, glucose transporter 1 ; $A C T B, \beta$-actine.

than 80 years of age; ii) be in clinical stage II/III based on the International Union Against Cancer TNM classification, with no evidence of distant metastases; iii) exhibit no invasion of the external sphincter muscle or elevator muscle of the anus; and iv) show no evidence of deep venous thrombosis. A total of 52 cases that received a curative operation and excluded pathological complete response were available for this study. The study design was approved by the hospital ethics review board. All patients signed informed consent forms allowing use of their tissues in this study.

5-Fluorouracil-based chemoradiotherapy regimen. Patients with rectal cancer were treated with short-course (a dose of $20 \mathrm{~Gy}$ in four fractions) or long-course (a dose of $45 \mathrm{~Gy}$ in 25 fractions) radiotherapy using a four-field box technique with concurrent chemotherapy to take advantage of 5-fluorouracil (5-FU) radio-sensitization. Patients underwent concurrent pharmacokinetic modulation chemotherapy (5-FU given by intravenous infusion, $600 \mathrm{mg} / \mathrm{m}^{2}$ for $24 \mathrm{~h}$ and tegafururacil (UFT) given orally, $400 \mathrm{mg} / \mathrm{m}^{2}$ ) orally for 5 days (16). Forty-one patients received short-course radiotherapy with chemotherapy over 1 week. The remaining eleven patients received long-course radiotherapy with chemotherapy for
4 weeks. The time interval between pre-operative CRT and surgery was 2-3 weeks for short-course irradiation patients, and 4-6 weeks for long-course irradiation patients. All patients underwent standard surgery, including total mesorectal excision, and received 5-FU-based adjuvant chemotherapy after surgery for 6 months to 1 year.

Clinical and pathological response to CRT. The clinical response after pre-operative CRT was evaluated by barium enema, endoscopy, computed tomography and magnetic resonance imaging, and was then graded as a complete response, a partial response, no change or progressive disease. Histological sections were sliced at a thickness of $5 \mu \mathrm{m}$ and stained with hematoxylin and eosin. The TRG method for sampling and examining the tumor site from colorectal excision specimens removed following neoadjuvant therapy was found in Bateman et al (17). The median number of sections per case examined was 4.5 (range, 2-7). TRG was evaluated using criteria from four sources: Japanese Society for Cancer of the Colon and Rectum (JSCCR) (18), Mandard et al (19), Dworak et al (20) and Rödel et al (3). Each TRG was evaluated by two investigators (K. Tanaka and Y. Okugawa) in a blinded fashion without knowledge of the clinical and pathological information. 
Microdissection and RNA extraction from formalin-fixed paraffin-embedded specimens. Microdissection of formalinfixed paraffin-embedded (FFPE) was performed as previously described (21). Microdissected specimens were digested with proteinase $\mathrm{K}$ in lysis buffer containing Tris- $\mathrm{HCl}$, ethylenediaminetetraacetic acid and sodium dodecyl sulfate, as previously published with minor modifications (22). RNA was purified by phenol/chloroform extraction and precipitated using ethanol. The concentration and quality of RNA was measured with UV absorbance at 260 and $280 \mathrm{~nm}$ (A260/280 ratio).

cDNA synthesis. The fragmented mRNA from FFPE tissue materials was reverse transcribed using random hexamer priming instead of oligo(dt)-based priming. cDNA was synthesized with random hexamers and Superscript III Reverse Transcriptase (Invitrogen, Carlsbad, CA) according to the manufacturer's instructions.

Quantitative real-time polymerase chain reaction. Real-time quantitative RT-PCR analysis was performed using a fluorescence-based real-time detection method (TaqMan) and an ABI PRISM 7700 Sequence Detection System (Applied Biosystems, Inc., Foster City, CA). Although SYBR-Green-based detection is less specific than TaqMan-based detection, we used SYBRGreen due to time and cost constraints. Primers were strictly selected or designed to span introns to avoid amplification from contaminating genomic DNA. Target sequences were kept as small as possible ( $\sim 100 \mathrm{bp}$ ) to ensure the detection of fragmented and partially degraded RNA. To confirm primer specificity, a single band of expected amplicon size for each target gene was verified using gel electrophoresis on a $2 \%$ agarose gel and visualized with ethidium bromide. Primers for PCNA, MKI67, CDKN1A ( p2I $\left.^{C i p l}\right)$, CDK2, CHEK1, PDRG1, LGR5, PROM1 (CD133), CD44, SOX2, POU5F1 (OCT4), LKB1, VEGF, EGFR, HGF, MET, HIF1, GLUT1, BAX, BCL2, GAPDH and $A C T B$ ( $\beta$-actin) were designed with Primer3 software (Biology Workbench Version 3.2, San Diego Supercomputer Center, University of California, San Diego). Primer sequences are shown in Table I. PCR was performed in a final volume of $25 \mu \mathrm{l}$ with a SYBR-Green PCR Master Mix using $1 \mu \mathrm{l}$ cDNA and $400 \mathrm{nM}$ of each primer for the respective genes. Cycling conditions were $50^{\circ} \mathrm{C}$ for $2 \mathrm{~min}$ and $95^{\circ} \mathrm{C}$ for $10 \mathrm{~min}$ followed by 40 cycles at $95^{\circ} \mathrm{C}$ for $15 \mathrm{sec}$ and $60^{\circ} \mathrm{C}$ for $1 \mathrm{~min}$.

Relative mRNA levels of target genes. The parameter $\mathrm{Ct}$ (threshold cycle) is defined as the fractional cycle number at which the fluorescence generated by cleavage of the probe passes a fixed threshold above baseline. The $\mathrm{Ct}$ is inversely proportional to the amount of cDNA, i.e., a higher $\mathrm{Ct}$ value means that more PCR cycles are required to reach a certain level of detection. Relative mRNA levels were determined using a standard curve. Standard curves and line equations were generated using 5-fold serially diluted solutions of cDNA from the LoVo colon cancer cell line or from qPCR Human Reference Total RNA (Clontech, Mountain View, CA). All standard curves were linear in the analyzed range with an acceptable correlation coefficient $\left(\mathrm{R}^{2}\right)$. Target gene expression was calculated using the standard curve. Quantitative normalization of cDNA in each sample was performed using expression of the $A C T B$ and $G A P D H$ gene as internal controls. Finally, mRNA levels of the target gene were presented as ratios between the genes of interest and the internal reference gene. Real-time PCR assays were performed twice for each sample and mean values were used for calculations of mRNA levels.

Statistical analyses. All statistical analyses were performed using Stat View 5.0 for Windows (SAS Institute Inc., Cary, NC). Values of each target gene are expressed as median values (inter-quartile range) in tables. Associations between continuous variables and categorical variables were evaluated using the Mann-Whitney U test for two groups. Recurrencefree survival (RFS) and overall survival (OS) time were calculated from the date of surgery to the date of disease recurrence and death, respectively. RFS and OS probability were calculated using the Kaplan-Meier product limit method; intergroup differences were determined using a log-rank test. Two-sided P-values of $<0.05$ were considered statistically significant.

\section{Results}

Patient and tumor characteristics. The median age of the patients was 64.5 years (range, 38-77 years) and the median follow-up period was 52 months (range, 3-129 months). The male to female ratio was 2.9:1. The median age was 64.5 years (range, 37-77 years) and the male to female ratio was 3.7:1. The post-CRT pathological T stages were pT1 $(n=5), \mathrm{pT} 2(\mathrm{n}=12)$, pT3 $(n=33)$ and pT4 $(n=2)$. Seventeen patients $(33 \%)$ had lymph node metastases. Forty-four tumors $(84.6 \%)$ showed well or moderately differentiated adenocarcinoma histology. Three patients (5.7\%) had local recurrence alone. A total of 12 patients (23.1\%) had distant recurrence. Patterns of distant recurrence were seen as liver and lung metastases in 2 patients, lung metastasis alone in 6 patients and peritoneal metastasis in 2 patients (Table II).

Evaluation of pathological response by TRG. Table III shows the pathological response after CRT using each TRG. Responders were categorized as patients with JSCCR TRG 2, Mandard TRG 2, Dworak and Rödel TRG 3. The others were non-responders. We excluded the cases with pathological complete response and no regression in this study (JSCCR TRG 0 and 3, Mandard TRG 1 and 5, Dworak TRG 0 and 4, Rödel TRG 0 and 4).

Gene expression profiles of residual cancer according to TRG. Total RNA was isolated from 52 specimens and transcriptional analysis was performed for 20 genes. Table IV shows the gene expression levels of residual cancer according to TRG. $L G R 5$ gene expression in non-responders was significantly higher than in responders among all TRG systems. Patients with elevated PDRGI and GLUTI gene expression had poor pathological response using the JSCCR, Dworak and Rödel TRG criteria. MKI67 gene expression in non-responders was significantly higher than in responders in the JSCCR and Rödel TRG systems. While, $B A X$ gene expression in responders was significantly higher than in non-responders in Mandard TRG system. Patients with poor pathological response based on the Rödel criteria had significantly higher gene expression of MKI67, PDRG1,LGR5, LKB1, EGFR, MET and GLUT1. 
Table II. Patient and tumor characteristics.

\begin{tabular}{|c|c|}
\hline Variables & $\mathrm{n}=52(\%)$ \\
\hline \multicolumn{2}{|l|}{ Age, median 64.5 years (range, $38-77$ ) } \\
\hline \multicolumn{2}{|l|}{ Gender } \\
\hline Male & $41(79.0)$ \\
\hline Female & $11(21.0)$ \\
\hline \multicolumn{2}{|l|}{ Pre-T classification } \\
\hline $1 / 2$ & $10(19.2)$ \\
\hline $3 / 4$ & $42(80.8)$ \\
\hline \multicolumn{2}{|l|}{ Pre-N classification } \\
\hline Negative & $17(32.7)$ \\
\hline Positive & $35(67.3)$ \\
\hline \multicolumn{2}{|l|}{ Pre-stage } \\
\hline $\mathrm{I} / \mathrm{II}$ & $17(32.7)$ \\
\hline III & $35(67.3)$ \\
\hline \multicolumn{2}{|l|}{ Down staging } \\
\hline No & $29(55.8)$ \\
\hline Yes & $23(44.2)$ \\
\hline \multicolumn{2}{|l|}{ Post-T classification } \\
\hline $1 / 2$ & $17(32.7)$ \\
\hline $3 / 4$ & $35(67.3)$ \\
\hline \multicolumn{2}{|l|}{ Post-N classification } \\
\hline Negative & $35(67.3)$ \\
\hline Positive & $17(32.7)$ \\
\hline \multicolumn{2}{|l|}{ Lymphatic invasion } \\
\hline Negative & $13(25.0)$ \\
\hline Positive & $39(75.0)$ \\
\hline \multicolumn{2}{|l|}{ Vascular invasion } \\
\hline Negative & $21(40.4)$ \\
\hline Positive & $31(59.6)$ \\
\hline \multicolumn{2}{|l|}{ Histology } \\
\hline Well/moderately & $44(84.6)$ \\
\hline Poorly/signet/mucinous & $8(15.4)$ \\
\hline \multicolumn{2}{|l|}{ Post-operative stage } \\
\hline $\mathrm{I} / \mathrm{II}$ & $33(63.5)$ \\
\hline III & $19(36.5)$ \\
\hline \multicolumn{2}{|l|}{ Radiation } \\
\hline Short, $20 \mathrm{~Gy} / 4$ fractions & $41(78.8)$ \\
\hline Long, $45 \mathrm{~Gy} / 25$ fractions & $11(21.2)$ \\
\hline \multicolumn{2}{|l|}{ Recurrence } \\
\hline None & $37(71.2)$ \\
\hline Local alone & $3(5.7)$ \\
\hline Distant with/without local failure & $12(23.1)$ \\
\hline
\end{tabular}

Recurrence-free and overall survival based on expression levels of PDRG1, LGR5 and GLUT1. We investigated whether the gene expression levels correlated with TRG were also associated with patient prognosis after pre-operative CRT followed by curative surgery because it has been reported as a predicter of clinical outcome. Four genes were selected (MKI67, PDRG1, LGR5 and GLUT1) that were significantly correlated with more than two TRG systems. The median value of MKI67,
Table III. Evaluation of pathological response by TRGs.

\begin{tabular}{|c|c|}
\hline Criteria & $\mathrm{n}=52(\%)$ \\
\hline \multicolumn{2}{|l|}{ JSCCR } \\
\hline TRG 0 & - \\
\hline TRG 1a & $13(25.0)$ \\
\hline TRG $1 \mathrm{~b}$ & $30(57.6)$ \\
\hline TRG 2 & $9(17.4)$ \\
\hline TRG 3 & - \\
\hline \multicolumn{2}{|l|}{ Mandard } \\
\hline TRG 1 & - \\
\hline TRG 2 & $15(28.8)$ \\
\hline TRG 3 & $23(44.2)$ \\
\hline TRG 4 & $14(27.0)$ \\
\hline TRG 5 & - \\
\hline \multicolumn{2}{|l|}{ Dworak } \\
\hline TRG 0 & - \\
\hline TRG 1 & $14(27.0)$ \\
\hline TRG 2 & $32(61.5)$ \\
\hline TRG 3 & $6(11.5)$ \\
\hline TRG 4 & - \\
\hline \multicolumn{2}{|l|}{ Rödel } \\
\hline TRG 0 & - \\
\hline TRG 1 & $10(19.2)$ \\
\hline TRG 2 & $22(42.3)$ \\
\hline TRG 3 & $20(38.5)$ \\
\hline TRG 4 & - \\
\hline
\end{tabular}

TRG, tumor regression grade. Cases with pathological complete response and no regression (JSCCR TRG 0 and 3, Mandard TRG 1 and 5, Dworak TRG 0 and 4, Rödel TRG 0 and 4) were excluded in this study.

PDRG1, LGR5 and GLUT1 gene expression was 0.00000895 , $0.0308,6.295$ and 0.566 , respectively. We categorized the case with more than the median value as the high gene expression group, and the remaining as the low group. Fig. 1 shows the survival curve for RFS according to each gene expression level using Kaplan-Meier analysis. Patients with $L G R$ expression levels above the cut-off values showed a significantly poorer RFS than did patients with expression levels below the cut-off values $(\mathrm{P}=0.0262)$. Patients in high MKI67 expression group had poorer RFS than that in low group without significant difference $(\mathrm{P}=0.0549)$. Patients with high GLUT1 gene expression had significantly poorer OS than those with low one (GLUT1 P=0.0093). MKI67, PDRG1 and LGR5 gene expression were not associated with $\mathrm{OS}$ (MKI67, $\mathrm{P}=0.6018 ; P D R G 1$, $\mathrm{P}=0.5493 ; L G R 5, \mathrm{P}=0.6487$ ) (data not shown).

\section{Discussion}

Rectal cancer is one of the most common cancers in Japan and the Western world. The introduction of pre-operative CRT and total mesorectal excision for the management of locally advanced rectal cancer significantly decreased local recur- 


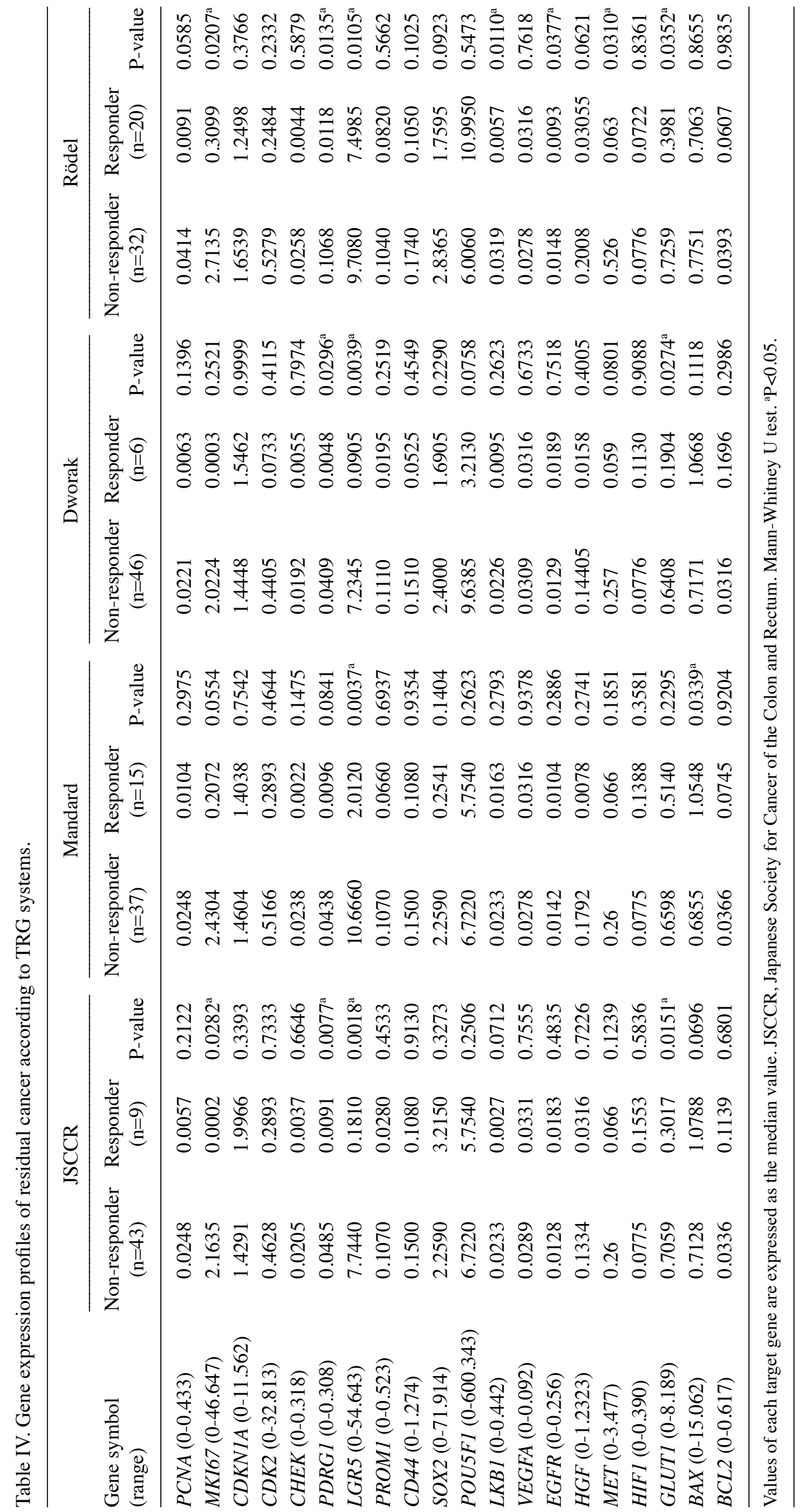


A

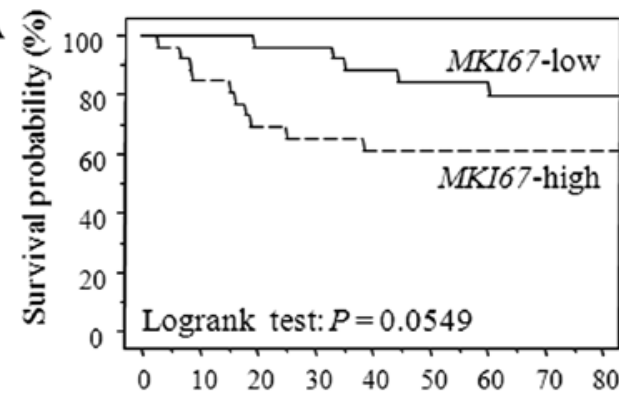

C

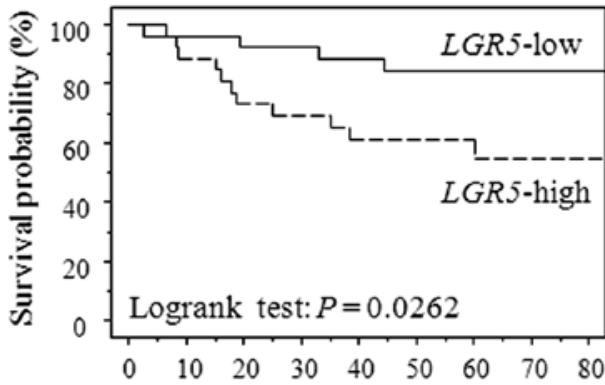

B

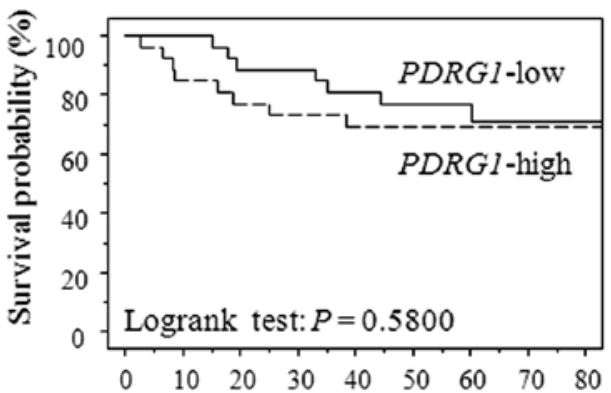

D

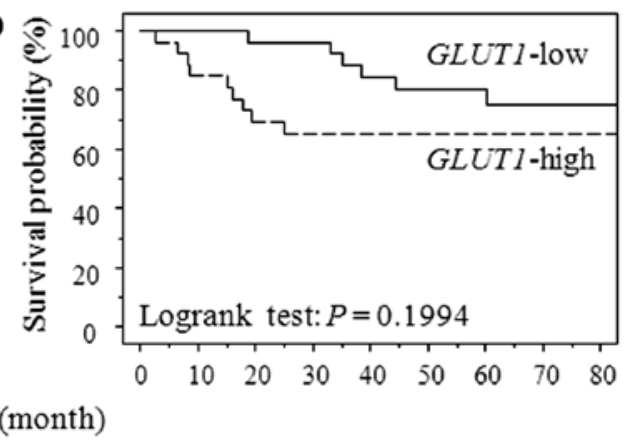

Figure 1. Kaplan-Meier curve for recurrence-free survival based on the expression of (A) MKI67, (B) PDRG1, (C) LGR5 and (D) GLUT1.

rence rates and improved sphincter preservation and patient survival (23-26). However, tumor recurrence remains the major cause of mortality in these patients, and the mechanism of tumor recurrence after pre-operative CRT remains unclear. In this study, the expression levels of 20 genes were correlated with TRG to determine if gene expression levels can be associated with tumor recurrence in locally advanced rectal cancer after pre-operative CRT.

Tumor down-staging, post-operative stage, N, T classification and TRG have been identified as important prognostic factors in rectal cancer patients following pre-operative CRT (3-8,27-29). We observed that advanced post-operative stage, the presence of lymph node metastasis and poor pathological response based on JSCCR and Rödel TRGs were significantly associated with recurrence-free survival in this study of 52 patients (log-rank test; post-operative stage, $\mathrm{P}=0.0137$; presence of lymph node metastasis, $\mathrm{P}=0.0244$; JSCCR, $\mathrm{P}=0.0464$; Rödel, $\mathrm{P}=0.0338$ ) (data not shown). Our data were similar to previous studies although down-staging and $\mathrm{T}$ classification were not associated with clinical outcome. Transcriptional analyses of gene expression according to TRG were then performed. To the best of our knowledge, there are few reports on the correlation between TRG and gene expression of residual cancer cells after pre-operative CRT. The expression levels of eight genes were correlated with TRGs. LGR5 gene expression levels in nonresponders was significantly higher than those in responders in all four TRG systems. LGR5 is a potential marker for stem cells in the small intestine and colon (30). Overexpression of LGR5 has also been implicated in colorectal carcinogenesis (31). Elevated PDRG1 and GLUT1 gene expression level was significantly correlated with poor pathological response in three of the four TRG systems (JSCCR, Dworak and Rödel). PDRG1 is regulated by DNA damage due to ultraviolet radiation and is implicated in tumor cell growth $(32,33)$. GLUT1 serves as a hypoxic indicator and is a hypoxic marker in colorectal cancer
(34). Immunohistochemistry of GLUT1 expression in pretreatment rectal cancer biopsy samples suggests that GLUT1 might be a useful predictive marker of response to CRT in rectal cancer (35). MKI67, LKB1, EGFR, MET and BAX expression levels were significantly correlated with one to two TRG systems. MKI67 is a proliferative marker (36) and LKBI has been implicated in the maintenance of hematopoietic stem cells and tumorigenesis through the suppression of apoptosis (37-39). $B C L 2 / B A X$ act as anti- or pro-apoptotic regulator. We observed that high $B A X$, but not $B C L 2$, expression was correlated with better pathological response based on Mandard TRG system. Reduction of $B A X$ function in human colorectal cancer cells has been associated with resistance to chemotherapy (40) and $B A X$ expression was correlated with outcome to neoadjuvant CRT (41) using imuunohistochemistry in pre-CRT samples. Our result suggested that post-CRT $B A X$ expression also might reveal the correlation of resistance to CRT. We examined whether gene expression of TRGs were associated with prognosis in rectal cancer after pre-operative CRT followed by surgery. We observed that patients with high LGR5 expression had significant correlation to RFS. Elevated GLUT1 expression was significantly associated with poor OS.

Biomarkers for tumor recurrence and prognosis after pre-operative CRT followed by curative surgery remain to be established. Our results may help identify prognostic predictors and clarify the strategy of adjuvant therapy for tumor recurrence after pre-operative CRT. However, it is not clear if the gene expressions correlated with TRGs are inherent or acquired after CRT due to the inability to compare expression levels between pre- and post-CRT samples. Therefore, these results did not directly show the predictive value of response to pre-operative CRT. We plan to examine the gene expression levels between pre-CRT biopsy and post-CRT samples.

In conclusion, TRG may reflect certain characteristics, such as proliferative activity, stemness potency and resistance 
to hypoxia, of residual cancer cells after pre-operative CRT. Moreover, the gene expression levels correlated with TRG were associated with poor recurrence-free survival in patients with locally advanced rectal cancer after neoadjuvant CRT. However, data in this study should be interpreted with some caution. The major limitation was the small number of patients, especially for patients with recurrence, and the retrospective nature of the study. A larger study population will allow us to validate these conclusions.

\section{Acknowledgements}

The authors would like to thank Yuka Kato and Motoko Ueda for providing excellent technical assistance.

\section{References}

1. Van den Brink M, Stiggelbout AM, van den Hout WB, et al: Clinical nature and prognosis of locally recurrent rectal cancer after total mesorectal excision with or without preoperative radiotherapy. J Clin Oncol 22: 3958-3964, 2004.

2. Collette L, Bosset JF, den Dulk M, et al: Patients with curative resection of cT3-4 rectal cancer after preoperative radiotherapy or radiochemotherapy: does anybody benefit from adjuvant fluorouracil-based chemotherapy? A trial of the European Organisation for Research and Treatment of Cancer Radiation Oncology Group. J Clin Oncol 25: 4379-4386, 2007.

3. Rodel C, Martus P, Papadoupolos T, et al: Prognostic significance of tumor regression after preoperative chemoradiotherapy for rectal cancer. J Clin Oncol 23: 8688-8696, 2005.

4. Vironen J, Juhola M, Kairaluoma M, et al: Tumour regression grading in the evaluation of tumour response after different preoperative radiotherapy treatments for rectal carcinoma. Int J Colorectal Dis 20: 440-445, 2005.

5. Vecchio FM, Valentini V, Minsky BD, et al: The relationship of pathologic tumor regression grade (TRG) and outcomes after preoperative therapy in rectal cancer. Int J Radiat Oncol Biol Phys 62: 752-760, 2005.

6. Bujko K, Michalski W, Kepka L, et al: Association between pathologic response in metastatic lymph nodes after preoperative chemoradiotherapy and risk of distant metastases in rectal cancer: an analysis of outcomes in a randomized trial. Int J Radiat Oncol Biol Phys 67: 369-377, 2007.

7. Dhadda AS, Dickinson P, Zaitoun AM, et al: Prognostic importance of Mandard tumour regression grade following preoperative chemo/radiotherapy for locally advanced rectal cancer. Eur J Cancer 47: 1138-1145, 2011.

8. Topova L, Hellmich G, Puffer E, et al: Prognostic value of tumor response to neoadjuvant therapy in rectal carcinoma. Dis Colon Rectum 54: 401-411, 2011.

9. Jorgensen TJ: Enhancing radiosensitivity: targeting the DNA repair pathways. Cancer Biol Ther 8: 665-670, 2009.

10. Maity A, McKenna WG and Muschel RJ: The molecular basis for cell cycle delays following ionizing radiation: a review. Radiother Oncol 31: 1-13, 1994.

11. Coleman CN: Hypoxia in tumors: a paradigm for the approach to biochemical and physiologic heterogeneity. J Natl Cancer Inst 80: $310-317,1988$

12. Overgaard J: Hypoxic radiosensitization: adored and ignored. J Clin Oncol 25: 4066-4074, 2007.

13. Deorukhkar A and Krishnan S: Targeting inflammatory pathways for tumor radiosensitization. Biochem Pharmacol 80: 1904-1914, 2010.

14. Baumann M, Krause M and Hill R: Exploring the role of cancer stem cells in radioresistance. Nat Rev Cancer 8: 545-554, 2008.

15. Zeki SS, Graham TA and Wright NA: Stem cells and their implications for colorectal cancer. Nat Rev Gastroenterol Hepatol 8: 90-100, 2011

16. Yoshikawa R, Kusunoki M, Yanagi H, et al: Dual antitumor effects of 5-fluorouracil on the cell cycle in colorectal carcinoma cells: a novel target mechanism concept for pharmacokinetic modulating chemotherapy. Cancer Res 61: 1029-1037, 2001.

17. Bateman AC, Jaynes E and Bateman AR: Rectal cancer staging post neoadjuvant therapy - how should the changes be assessed? Histopathology 54: 713-721, 2009.
18. Japanese Society for Cancer of the Colon and Rectum: General rules for clinical and pathological studies on cancer of the colon, rectum and anus. Kanehara \& Co., Tokyo, 2006.

19. Mandard AM, Dalibard F, Mandard JC, et al: Pathologic assessment of tumor regression after preoperative chemoradiotherapy of esophageal carcinoma. Clinicopathologic correlations. Cancer 73: 2680-2686, 1994.

20. Dworak O, Keilholz L and Hoffmann A: Pathological features of rectal cancer after preoperative radiochemotherapy. Int J Colorectal Dis 12: 19-23, 1997.

21. Saigusa S, Tanaka K, Toiyama Y, et al: Correlation of CD133, OCT4, and SOX2 in rectal cancer and their association with distant recurrence after chemoradiotherapy. Ann Surg Oncol 16: 3488-3498, 2009.

22. Bijwaard KE, Aguilera NS, Monczak Y, et al: Quantitative real-time reverse transcription-PCR assay for cyclin D1 expression: utility in the diagnosis of mantle cell lymphoma. Clin Chem 47: 195-201, 2001.

23. Sauer R, Becker H, Hohenberger W, et al: Preoperative versus postoperative chemoradiotherapy for rectal cancer. N Engl J Med 351: 1731-1740, 2004.

24. Gerard JP, Chapet O, Nemoz C, et al: Improved sphincter preservation in low rectal cancer with high-dose preoperative radiotherapy: the lyon R96-02 randomized trial. J Clin Oncol 22: 2404-2409, 2004.

25. Guillem JG, Chessin DB, Cohen AM, et al: Long-term oncologic outcome following preoperative combined modality therapy and total mesorectal excision of locally advanced rectal cancer. Ann Surg 241: 829-838, 2005.

26. Bosset JF, Collette L, Calais G, et al: Chemotherapy with preoperative radiotherapy in rectal cancer. N Engl J Med 355: 1114-1123, 2006

27. Kaminsky-Forrett MC, Conroy T, Luporsi E, et al: Prognostic implications of downstaging following preoperative radiation therapy for operable T3-T4 rectal cancer. Int J Radiat Oncol Biol Phys 42: 935-941, 1998.

28. Chapet O, Romestaing P, Mornex F, et al: Preoperative radiotherapy for rectal adenocarcinoma: which are strong prognostic factors? Int J Radiat Oncol Biol Phys 61: 1371-1377, 2005.

29. Kim TH, Chang HJ, Kim DY, et al: Pathologic nodal classification is the most discriminating prognostic factor for disease-free survival in rectal cancer patients treated with preoperative chemoradiotherapy and curative resection. Int J Radiat Oncol Biol Phys 77: 1158-1165, 2010.

30. Barker N, van Es JH, Kuipers J, et al: Identification of stem cells in small intestine and colon by marker gene Lgr5. Nature 449: 1003-1007, 2007.

31. Uchida H, Yamazaki K, Fukuma M, et al: Overexpression of leucine-rich repeat-containing $\mathrm{G}$ protein-coupled receptor 5 in colorectal cancer. Cancer Sci 101: 1731-1737, 2010.

32. Luo X, Huang Y and Sheikh MS: Cloning and characterization of a novel gene PDRG that is differentially regulated by p53 and ultraviolet radiation. Oncogene 22: 7247-7257, 2003.

33. Jiang L, Luo X, Shi J, et al: PDRG1, a novel tumor marker for multiple malignancies that is selectively regulated by genotoxic stress. Cancer Biol Ther 11: 567-573, 2011.

34. Chung FY, Huang MY, Yeh CS, et al: GLUT1 gene is a potential hypoxic marker in colorectal cancer patients. BMC Cancer 9: 241, 2009

35. Brophy S, Sheehan KM, McNamara DA, et al: GLUT-1 expression and response to chemoradiotherapy in rectal cancer. Int J Cancer 125: 2778-2782, 2009.

36. Hofstadter F, Knuchel R and Ruschoff J: Cell proliferation assessment in oncology. Virchows Arch 427: 323-341, 1995.

37. Herrmann JL, Byekova Y, Elmets CA, et al: Liver kinase B1 (LKB1) in the pathogenesis of epithelial cancers. Cancer Lett 306: 1-9, 2011.

38. Gurumurthy S, Xie SZ, Alagesan B, et al: The Lkb1 metabolic sensor maintains haematopoietic stem cell survival. Nature 468: 659-663, 2010.

39. Gan $\mathrm{B}, \mathrm{Hu}$ J, Jiang $\mathrm{S}$, et al: Lkb1 regulates quiescence and metabolic homeostasis of haematopoietic stem cells. Nature 468: 701-704, 2010.

40. Yamaguchi $\mathrm{H}$, Bhalla $\mathrm{K}$ and Wang HG.: Bax plays a pivotal role in thapsigargin-induced apoptosis of human colon cancer HCT116 cells by controlling Smac/Diablo and Omi/HtrA2 release from mitochondria. Cancer Res 63: 1483-1489, 2003.

41. Chang HJ, Jung KH, Kim DY, et al: Bax, a predictive marker for therapeutic response to preoperative chemoradiotherapy in patients with rectal carcinoma. Hum Pathol 36: 364-371, 2005. 